\title{
Intracranial Pressure Monitors in Traumatic Brain Injury: A Systematic Review
}

\author{
Asher A. Mendelson, Chris Gillis, William R. Henderson, Juan J. Ronco, \\ Vinay Dhingra, Donald E. G. Griesdale
}

\begin{abstract}
We conducted a systematic review to examine the relationship between intracranial pressure monitors (ICP) monitors and mortality in traumatic brain injury (TBI). We systematically searched for articles that met the following criteria: (1) adults patients, (2) TBI, (3) use of an ICP monitor, (4) point estimate for mortality with ICP monitoring (5) adjustment for potential confounders. Six observational studies were identified with 11,371 patients. There was marked between-study heterogeneity that precluded a pooled analysis. Patients with ICP monitors had different clinical characteristics and received more ICP targeted therapy in the ICU. Four studies found no significant relationship between ICP monitoring and survival, while the other two studies demonstrated conflicting results. Significant confounding by indication in observational studies limits the examination of isolated TBI interventions. More research should focus on interventions that affect TBI careplan systems. Further research is needed to identify which subset of severe TBI patients may benefit from ICP monitoring.
\end{abstract}

RÉSUMÉ: Moniteurs de la pression intracrânienne dans les traumatismes crâniens graves : une revue systématique. Nous avons effectué une revue systématique de la littérature pour examiner la relation entre les moniteurs de la pression intracrânienne (PIC) et la mortalité dans les traumatismes crâniens (TC). Nous avons recherché systématiquement les articles qui rencontraient les critères suivants : 1) des patients adultes; 2) un TC; 3) l'utilisation d'un moniteur de la PIC; 4) une estimation ponctuelle de la mortalité lorsque la surveillance de la PIC était effectuée; 5) l'ajustement des facteurs de confusion potentiels. Six études d'observation ont été identifiées auxquelles un total de 11371 patients avaient participé. Il existait une hétérogénéité marquée entre les études, ce qui excluait la possibilité de regrouper les données. Les caractéristiques cliniques des patients sous surveillance de la PIC étaient différentes et ces patients recevaient plus de traitements ciblant la PIC à l'unité des soins intensifs. Quatre études n'ont pas montré de relation significative entre la surveillance de la PIC et la survie alors que les résultats des deux autres études étaient contradictoires. Dans les études d'observation, l'examen d'interventions isolées dans le TC est limité par un facteur confondant important, l'indication de ces interventions. Les recherches devraient cibler les interventions qui touchent les plans de traitement dans le TC. Il faudrait procéder à des études plus approfondies dans le but d'identifier quel sous-groupe de patients atteints d'un TC sévère est susceptible de bénéficier de la surveillance de la PIC.

Can J Neurol Sci. 2012; 39: 571-576

Traumatic Brain Injury (TBI) is a significant cause of mortality and morbidity around the world. The United States experiences an average of 235,000 hospitalizations and 50,000 deaths from TBI annually ${ }^{1}$. Although neurocritical care has evolved dramatically since its inception in the 1950s, the mortality from a severe TBI remains significant ${ }^{2-5}$.

Elevated intracranial pressure (ICP) is an important cause of secondary brain injury and is consistently associated with worse neurologic outcomes in patients following $\mathrm{TBI}^{6-10}$. Given this, ICP monitoring is currently a level II recommendation from the Brain Trauma Foundation (BTF) in patients with severe TBI Glasgow Coma Scale $(\mathrm{GCS})<=8)^{11}$.

Despite these recommendations, there exists significant variability in the use of ICP monitors across different hospitals and countries ${ }^{4,12-15}$. This may reflect conflicting or absent clinical evidence as to the benefit of ICP monitoring ${ }^{16-18}$. Although a Cochrane review on the topic was recently published, no studies were analyzed as they included only randomized trials ${ }^{19}$. Without considering observational studies, this review was unable to provide any conclusions as to the value of ICP monitoring in patients with TBI. In this context, we conducted a systematic review of observational studies to evaluate the evidence examining the relationship between use of ICP monitors and mortality in patients with severe TBI.

\section{METHODS}

This article reports our systematic review in accordance with the Meta-analysis Of Observational Studies in Epidemiology (MOOSE) guidelines ${ }^{20}$.

From the Department of Medicine (AAM, WRH, JJR, VD, DEGG), Deparment of Surgery, Division of Neurosurgery (CG), Department of Anesthesia, Pharmacology and Therapeutics (DEGG), University of British Columbia and Department of Anesthesia, Vancouver General Hospital; Program of Critical Care Medicine (WRH, JJR, VD, DEGG), Vancouver General Hospital; Centre for Clinical Epidemiology and Evaluation (DEGG), Vancouver Coastal Health Research Institute, Vancouver, British Columbia, Canada.

Received January 16, 2012. Final Revisions Submitted April 2, 2012. Correspondence to: Donald Griesdale, Department of Anesthesia \& Program of Critical Care Medicine, Vancouver General Hospital Room 2438, Jim Pattison Pavilion, 2nd Floor 855 West 12th Avenue Vancouver, British Columbia, V5Z 1M9, Canada. Email: donald.griesdale@vch.ca. 


\section{Search Strategy}

We systematically searched MEDLINE (1966 - October 2011) and EMBASE (1977 - October 2011) for observational studies and trials examining the effect of ICP monitors on mortality. We hand searched online abstracts of selected conferences from 2000 - 2009, including: American Thoracic Society (ATS), the American College of Chest Physicians (Chest), the American Association for the Surgery of Trauma, the American Association of Neurological Surgeons, and the Congress of Neurological Surgeons. We also hand searched bibliographies of all relevant studies.

For the bibliographic review of MEDLINE, we constructed search filters for ICP monitors and TBI using a combination of exploded Medical Subject Heading (MeSH) terms and text words, all combined with the Boolean OR operator. The ICP filter contained text words: subarachnoid bolt, subdural monitoring, intraparenchymal monitor, intraventricular drain, intracranial pressure monitor, icp monitor, external ventricular drain, ventriculostomy, and evd. The TBI filter contained the $\mathrm{MeSH}$ term craniocerebral trauma and text words: closed head injury, closed head trauma, traumatic brain injury, brain injury, tbi and chi. We then combined both filters using the Boolen operator AND. A similar search strategy was employed for EMBASE. These search methods can be found in the Appendix.

\section{Search Criteria}

In duplicate and independently, two authors (AM and CG) screened all articles using the following inclusion criteria: (1) adult patients, (2) traumatic brain injury, (3) use of an ICP monitor, (4) presented a point estimate and 95\% confidence interval for mortality for ICP monitoring (compared to no ICP monitoring), and (5) described adjustment for potential confounders.

\section{Data Abstraction}

Independently and in duplicate, two authors (AM and CG) abstracted the following data: mortality, type of TBI, duration of intensive care and hospitalization, duration of mechanical ventilation, admission GCS, severity of illness, presence of hypotension on admission (systolic blood pressure $\leq=90$ ). Authors were contacted to obtain unpublished data $^{4,21}$ and articles were not excluded if they were published in a language other than English ${ }^{22}$. Disagreement was resolved by discussion and arbitrated by the third author (D.G.) if necessary.

\section{Results}

\section{Literature Search}

Searching the electronic databases revealed a total of 351 unique citations. We excluded 268 by screening titles and abstracts resulting in 83 articles for full text review. Seventyseven publications were excluded for reasons listed in the Figure, leaving a total of six studies included in this systematic review ${ }^{4,15,16,21,23,24}$. Study characteristics, outcomes, and clinical variables are listed in the Table.

\section{Assessment of Methodological Quality and Bias}

All six studies were retrospective and non-randomized with respect to ICP monitoring. The inclusion and exclusion criteria for each study were not uniform. Although each of the six studies conducted a multivariate analysis, the variables used by the authors were not homogenous; studies included anywhere from three to eight independent clinical variables. Some studies failed to adjust for age ${ }^{15,16,21}, \mathrm{GCS}^{15,24}$, or pupillary response $\mathrm{e}^{4,15,16,23,24}$ which are all considered to exert profound influences on outcome in $\mathrm{TBI}^{25,26}$. Ultimately, between-study heterogeneity precluded pooled analysis of the data included in these studies.

\section{ICP monitors and mortality}

Lane $^{15}$ and colleagues demonstrated an overall harm to ICP monitor insertion on univariate analysis (OR 1.24, p <0.032). However, after controlling for injury severity (maximum Abbreviated Injury Scale (AIS) head and Injury Severity Score (ISS)) and mechanism, ICP monitoring was associated with improved survival (Mortality OR $0.769 \mathrm{p}<0.015$ ). In contrast, Shafi ${ }^{16}$ and colleagues found ICP monitor insertion to be associated with significantly worse survival for both univariate and multivariate analysis (Survival OR 0.55, 0.39-0.76 $\mathrm{p}<0.0001$; multivariate analysis). Mauritz ${ }^{23}$ and colleagues demonstrated that ICP monitoring was associated with an overall lower ICU mortality on unadjusted analysis (Survival OR 1.17, $95 \%$ CI: $1.15-1.2, \mathrm{p}<0.05)$. However, in a subgroup of patients with a GCS $>8$, ICP monitoring was associated with increased ICU mortality (data presented only graphically in manuscript). Moreover, the reduction in ICU mortality with ICP monitoring

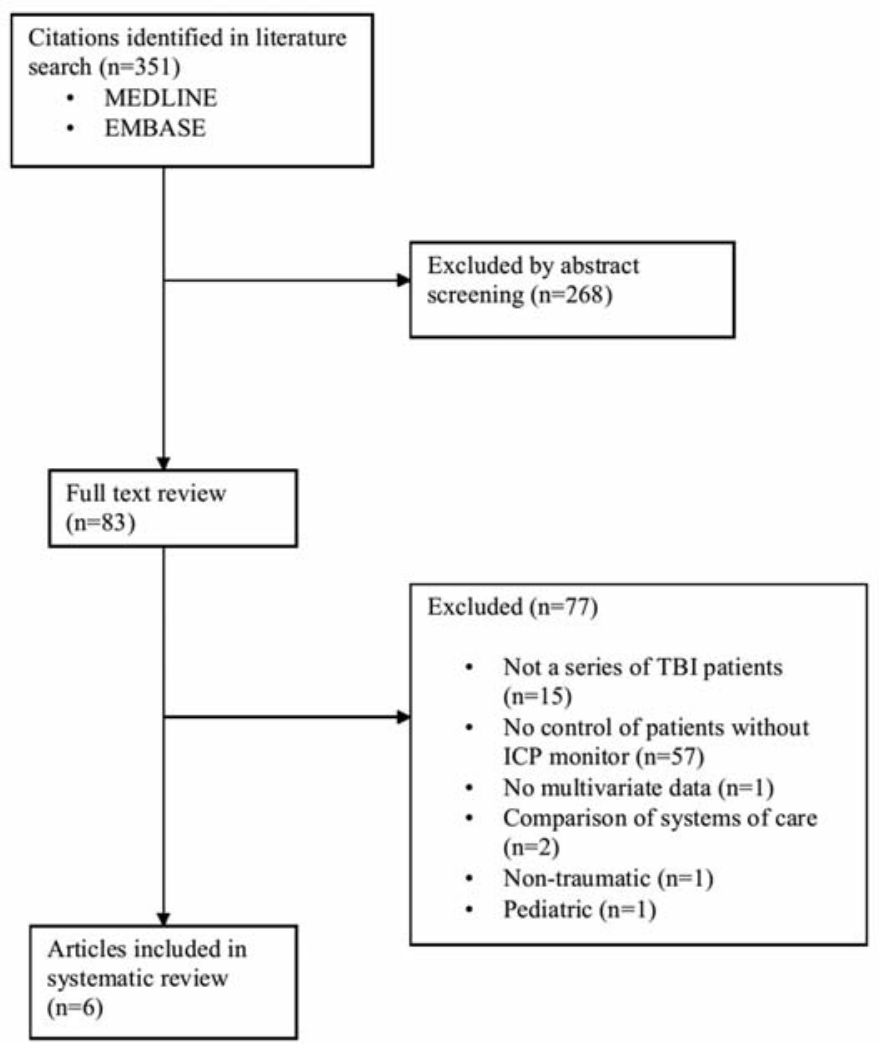

Figure: Flowchart for study selection. Search: MEDLINE (1966-2011) + EMBASE (1977-2011) 
Table: Overview of studies included in systematic review

\begin{tabular}{|c|c|c|c|c|c|c|c|}
\hline \begin{tabular}{c|} 
Author, $\mathbf{Y r}$ \\
Number of Patients
\end{tabular} & Study Design & Inclusion Criteria & Exclusion Criteria & $\begin{array}{c}\text { ICP monitored, } \\
\text { n (\%) }\end{array}$ & Type of ICP monitor & Crude Outcome ICP group & $\begin{array}{c}\text { Multivariate } \\
\text { Outcome ICP Group }\end{array}$ \\
\hline $\begin{array}{l}\text { Lane 2000 } \\
\mathrm{n}=5,507\end{array}$ & $\begin{array}{l}\text { Retrospective } \\
\text { cohort }\end{array}$ & AIS head $>3$ & None stated & $541(10 \%)$ & Not specified & Mortality OR 1.24, $\mathrm{p}<0.032$ & $\begin{array}{c}\text { Mortality OR } \\
0.77, p=0.015\end{array}$ \\
\hline $\begin{array}{l}\text { Mauritz 2007 } \\
\mathrm{n}=415\end{array}$ & $\begin{array}{l}\text { Retrospective } \\
\text { cohort }\end{array}$ & GCS $<9$ & $\begin{array}{c}\text { Died before admission to } \\
\text { hospital }\end{array}$ & $264(63 \%)$ & $\begin{array}{c}\text { Intraparenchymal } 77 \% \\
\text { EVD 10\% } \\
\text { Epidural 3\% } \\
\text { Unknown 2\% } \\
\text { Combined 8\% }\end{array}$ & $\begin{array}{c}\text { Survival OR } 1.17,1.5-1.2, \\
\text { p }<0.05 \\
\text { Improved 90-day outcome } \\
\text { (42\% vs } 33 \%)\end{array}$ & $\begin{array}{l}\text { NS } \\
\text { NS }\end{array}$ \\
\hline $\begin{array}{l}\text { Mauritz 2008 } \\
\mathrm{n}=1856\end{array}$ & $\begin{array}{c}\text { Retrospective } \\
\text { cohort }\end{array}$ & AIS head $>2$ & $\begin{array}{l}\text { Discharged from } \\
\text { hospital }<4 \text { days }\end{array}$ & $825(56 \%)$ & Not specified & $\begin{array}{c}\text { ICU mortality } \mathrm{p}=\mathrm{NS} \\
\text { Hospital mortality } \mathrm{p}=\mathrm{NS}\end{array}$ & $\begin{array}{l}\text { NS } \\
\text { NS }\end{array}$ \\
\hline $\begin{array}{l}\text { Thompson 2008 } \\
\mathrm{n}=1776\end{array}$ & $\begin{array}{l}\text { Retrospective } \\
\text { cohort }\end{array}$ & $\begin{array}{l}\text { Any TBI ICD code } \\
\text { Age } 24-65\end{array}$ & $\begin{array}{c}\text { Dead on arrival, } \\
\text { homeless, } \\
\text { non-US citizen }\end{array}$ & $281(16 \%)$ & Not specified & $\begin{array}{c}\text { Hospital death RR } \\
0.94,0.79-1.12 \mathrm{p}=\mathrm{NS} \\
\\
12 \text {-month death RR } \\
1.07,0.87-1.32 \mathrm{p}=\mathrm{NS}\end{array}$ & $\begin{array}{c}\text { Hospital death RR } \\
0.94,0.81-1.09 \mathrm{p}=\mathrm{NS} \\
\\
12 \text {-month death RR } \\
1.15,0.97-1.36 \mathrm{p}=\mathrm{NS}\end{array}$ \\
\hline $\begin{array}{l}\text { Shafi 2008 } \\
\mathrm{n}=1646\end{array}$ & $\begin{array}{l}\text { Retrospective } \\
\text { cohort }\end{array}$ & $\begin{array}{c}\text { GCS }<9 \\
\text { AIS head }>2 \\
\text { Postive CT head } \\
\text { Age 20-50 }\end{array}$ & $\begin{array}{c}\text { Dead within } \\
48 \text { hrs } \\
\text { ICU stay }<3 \text { days }\end{array}$ & $708(43 \%)$ & Not specified & $\begin{array}{c}\text { Survival OR 0.55, 0.42-0.72 } \\
\mathrm{p}<0.0001\end{array}$ & $\begin{array}{c}\text { Survival OR } 0.55,0.39-0.76 \\
\mathrm{p}<0.0001\end{array}$ \\
\hline $\begin{array}{l}\text { Griesdale } \mathbf{2 0 1 0}^{24} \\
\mathrm{n}=171\end{array}$ & $\begin{array}{l}\text { Retrospective } \\
\text { cohort }\end{array}$ & GCS $<9$ & $\begin{array}{l}\text { Obeying commands or } \\
\text { dead within } 12 \text { hrs } \\
\text { High c-spine injury }\end{array}$ & $98(57 \%)$ & EVD $100 \%$ & $\begin{array}{c}\text { 28-day mortality } \\
(22 \% \text { vs } 12 \%) p=0.07 \\
\\
\text { Hospital mortality } \\
(29 \% \text { vs } 12 \%) p<0.01\end{array}$ & $\begin{array}{c}\text { 28-day mortality } \\
\text { OR 2.1, 0.80-5.6 } \mathrm{p}=0.13 \\
\text { Hospital mortality } \\
\text { OR } 2.8,1.1-7.1 \mathrm{p}=0.04\end{array}$ \\
\hline
\end{tabular}

ICP, intracranial pressure; AIS, Abbreviated Injury Scale; ISS, Injury Severity Score; RTS, Revised Trauma Score; GCS, Glasgow Coma Scale; TBI, traumatic brain injury; ICD, International Classification of Diseases; RR, risk ratio; OR, odds ratio; NS, not significant; CT, computerized tomography.

did not persist after multivariate regression analysis. Similar findings were demonstrated by Griesdale and colleagues ${ }^{24}$. Although ICP monitoring was associated with increased hospital mortality on adjusted analysis (OR 2.8, 95\% CI: $1.1-7.1$, $\mathrm{p}=0.04$ ), these results were entirely driven by those patients who had a GCS $\geq 6$ (OR 5.6, 95\% CI: $1.7-18.4, \mathrm{p}<0.01)$. In contrast, those patients with a GCS $<6$ had no increased risk of mortality with ICP monitoring (OR 0.76, 95\% CI: $0.18-3.2, \mathrm{p}=0.71$ ). Finally, Thompson ${ }^{21}$ and Mauritz ${ }^{4}$ found no significant effect of ICP monitor insertion on survival with univariate or multivariate analysis.

\section{Baseline Patient Characteristics}

All six studies identified at least one clinical variable that differed significantly between the group of patients that received ICP monitoring and the controls. Patients in whom an ICP monitor was inserted were younger ${ }^{4,15,21,23,24}$, had higher injury severity scores ${ }^{4,15,16,23}$, more hypotension ${ }^{4}$, and lower $\mathrm{GCS}^{24}$.

\section{Intensity of Care in the ICU}

The proportion of cohort patients receiving ICP monitors was highly variable, ranging from 10\%-63\%. Only two studies reported the type of ICP monitor that was used ${ }^{23,24}$. The use of ventricular drains was markedly different in both of these studies (100\% vs 10\%). Patients with ICP monitors received more therapy targeted towards ICP reduction (i.e. mannitol, hypertonic saline, hypothermia, hyperventilation $)^{23,24}$, had more invasive procedures (i.e. craniotomy, jugular bulb monitor) ${ }^{16,24}$, and spent more days ventilated and in the intensive care unit ${ }^{4,15,16,24}$.
Table: continued

\begin{tabular}{|c|c|c|}
\hline & $\begin{array}{l}\text { Variables included in } \\
\text { Multivariate Analysis }\end{array}$ & Points of Interest \\
\hline Lane 2000 ${ }^{15}$ & $\begin{array}{l}\text { Mechanism of injury } \\
\text { AIS Head } \\
\text { ISS }\end{array}$ & $\begin{array}{l}\text { Only } 61 \% \text { of cohort had complete GCS } \\
\text { documentation }\end{array}$ \\
\hline Mauritz $2007^{23}$ & $\begin{array}{l}\text { Age } \\
\text { ISS } \\
\text { GCS }\end{array}$ & $\begin{array}{l}\text { ICP patients were younger, more severely } \\
\text { injured, and were more likely to receive mannitol } \\
\text { or hypertonic saline }\end{array}$ \\
\hline Mauritz 2008 $^{4}$ & $\begin{array}{l}\text { SAPS II (includes age, GCS) } \\
\text { Gender } \\
\text { AIS head } \\
\text { Large volume replacement } \\
\text { Isolated TBI } \\
\text { Volume of TBI per centre }\end{array}$ & $\begin{array}{l}\text { Included a multivariate regression analysis for } \\
\text { factors influencing the use of ICP monitor }\end{array}$ \\
\hline Thompson 2008 ${ }^{21}$ & $\begin{array}{l}\text { ISS } \\
\text { GCS-M } \\
\text { Midline shift } \\
\text { Pupillary response } \\
\text { AIS Head } \\
\text { Gender } \\
\text { Charlson score } \\
\end{array}$ & $\begin{array}{l}\text { Only cohort that included non-severe TBI (GCS } \\
>8 \text { ) } \\
\text { Registry included non-trauma hospitals }\end{array}$ \\
\hline Shafi 2008 ${ }^{16}$ & $\begin{array}{l}\text { ISS } \\
\text { RTS } \\
\text { AIS head } \\
\text { Craniotomy } \\
\text { GCS-M } \\
\text { Spine injuries } \\
\text { Pre-morbid cardiac disease } \\
\text { ICU complications }\end{array}$ & $\begin{array}{l}\text { ICP patients had higher injury severity scores, } \\
\text { were less likely to have a positive alcohol screen, } \\
\text { and spent longer time in the ICU }\end{array}$ \\
\hline Griesdale $\mathbf{2 0 1 0}^{24}$ & $\begin{array}{l}\text { Age } \\
\text { APACHE } \\
\text { Positive CT findings } \\
\text { Mannitol } \\
\text { Year of admission } \\
\text { Hypotension } \\
\text { Hypoxia } \\
\text { Craniotomy }\end{array}$ & $\begin{array}{l}\text { Demonstrated a binary effect in mortality } \\
\text { outcomes with ICP monitoring; patients with } \\
\text { GCS } \geq 6 \text { had worse outcomes with monitoring }\end{array}$ \\
\hline
\end{tabular}




\section{DISCUSSION}

In this systematic review, we demonstrated that there is large amount of between study heterogeneity examining the role of ICP monitoring and outcomes following traumatic brain injury that precluded performing a pooled analysis. There were frank differences both within and between studies in terms of which patients were chosen for ICP monitoring, the definition of severe TBI, the type of ICP monitor used, and the levels of intervention offered to each group of patients. Not surprisingly, there were conflicting mortality outcomes attributable to ICP monitoring, partly explained by the observed heterogeneity.

Because these studies are all observational and nonrandomized, the decision to insert an ICP monitor has already been made by the neurocritical care team prior to the onset of the study. Therefore, this decision may be influenced by factors relating to patients' pre-morbid conditions, the severity of the current TBI, and centre-specific practices and preferences. Thus, much like other therapies in medicine, the use of ICP monitoring is subject to strong confounding by indication ${ }^{27}$. Confounding by indication occurs when variables that are associated with an outcome in the study base are also associated with the exposure. Consequently, even with multivariable adjustment, determining an unbiased outcome estimate for ICP monitors in these studies is extremely difficult. This is exacerbated by the generally small samples sizes of the published studies that limits confounding adjustment. Despite straightforward BTF indications for ICP monitoring, it is clear that clinicians do not strictly adhere to the BTF guidelines. Whether this reflects an acknowledged lack of evidence or skepticism as to the relevance of the guidelines remains unclear. Nevertheless, this lack of uniform application of the BTF guidelines deserves further consideration.

Although confounding by indication may be an alternate explanation for the mixed results in these studies, ICP monitoring may still influence outcomes independently and therefore deserves closer attention. Being a monitoring device, a distinction must be made between the information obtained from the ICP monitor and the interventions instituted based on this information. For example, change in management based on ICP measurements can be instituted within an ICP, Cerebral Prefusion Pressure (CPP), or Lund-based TBI protocol ${ }^{28}$. Moreover, ideal ICP and CPP target values have yet to be identified. Furthermore, clinicians may decide to use only the quantitative value of ICP while others may additionally use the ICP waveform to direct management ${ }^{29}$. Therefore, by refining and optimizing the use of ICP monitors, clinicians may be able to elicit indications and benefits from ICP monitors that are not currently evident.

Our review also demonstrates that patients who receive ICP monitoring are subject to increased interventions based on this information. Another observational study in patients with TBIs demonstrated that compared to hospitals without ICP monitoring, those with ICP / CPP targeted therapy had increased intensity of therapy as defined by increased use of sedatives, mannitol, vasopressors and barbiturates ${ }^{30}$. This has also been discussed with respect to other monitoring devices including the pulmonary artery catheter ${ }^{31}$ and brain tissue oxygen monitoring $\left(\mathrm{PbO}_{2}\right)^{32}$. Ultimately, we hope that the information gained from these monitoring devices will lead to interventions that improve outcomes. Yet, many of our current therapies for increased ICP such as sedation and pharmacologic paralysis are potentially associated with worse outcomes in critically ill patients ${ }^{33,34}$. Thus, in order for any monitoring device to independently improve outcome, it must be: (1) used in the appropriate patient population, (2) accurate and reliable, (3) used with minimal complications (4) correctly interpreted within the clinical context (5) be acted upon in a standardized and reproducible manner, and (6) dictate interventions that generate positive outcomes. Although there are challenges with all of these criteria, certainly the specific patient population that may benefit from ICP monitoring has yet to be clearly defined. This review highlights the interplay between confounding variables, monitoring devices, treatment philosophies, and clinical outcomes; it speaks to the inherent complexity of delivering neurocritical care.

Improvements to entire systems of care may lead to better outcomes in patients with TBI. Several studies have looked at the outcomes of severe TBI before and after the institution of ICP protocoled centre-specific guidelines ${ }^{35-39}$. Not only have these studies demonstrated improved outcomes after guideline institution, but one study ${ }^{39}$ demonstrated improved survival with the new protocol despite a dramatic reduction in the rates of ICP monitoring ( $35 \%$ vs $9 \%$ ). Another study ${ }^{40}$ found that by simply displaying CPP values prominently in the ICU, investigators were able to improve survival in severe TBI patients. Given many of the aforementioned limitations in TBI research, perhaps focusing on the system at large, rather than isolated elements, will yield stronger and more clinically relevant advances in TBI care.

Major limitations of our systematic review are the few studies available that met our inclusion criteria, and the marked between-study heterogeneity. However, we were able to examine this heterogeneity by exploring differences in ICP monitor utilization and outcomes, which itself is clinically relevant information. As with all observational studies, or systematic review of observational studies, residual or unmeasured confounding remains an alternate explanation for our findings.

\section{Conclusions}

The isolated benefit of ICP monitoring in severe TBI is not clearly established. Clinical evidence is lacking as to the efficacy of ICP monitoring mostly attributed to the heterogeneous nature of the studies available on this topic. The significant modification of signal effect by confounding variables suggests that outcomes in severe TBI relate to both the presentation of the patient and the overall delivery of care rather than specific elements within the system. This theory is supported by emerging evidence suggesting that guideline-driven management of severe TBI improves patient outcome. Future studies are warranted to investigate the ideal design of a practical TBI protocol for standardized use and also to explore the current barriers to standardized TBI management that exist. Research should also focus on identifying distinct subgroups of severe TBI patients who may benefit from monitoring and optimizing ICP-directed care in patients undergoing monitor-based therapy.

\section{Disclosure}

Dr. Griesdale is funded by a Mentored Clinician Scientist Award from the Vancouver General Hospital and UBC Hospital Foundation. 


\section{REFERENCES}

1. Langlois JA, Rutland-Brown W, Wald MM. The epidemiology and impact of traumatic brain injury: a brief overview. J Head Trauma Rehabil. 2006;21:375-8.

2. Becker DP, Miller JD, Ward JD, Greenberg RP, Young HF, Sakalas $\mathrm{R}$. The outcome from severe head injury with early diagnosis and intensive management. J Neurosurg. 1977;47:491-502.

3. Marshall LF, Smith RW, Shapiro HM. The outcome with aggressive treatment in severe head injuries. Part I: the significance of intracranial pressure monitoring. J Neurosurg. 1979;50:20-5.

4. Mauritz W, Steltzer H, Bauer P, Dolanski-Aghamanoukjan L, Metnitz P. Monitoring of intracranial pressure in patients with severe traumatic brain injury: an Austrian prospective multicenter study. Intensive Care Med. 2008:34:1208-15.

5. Myburgh JA. Cooper DJ, Finfer SR, et al. Australasian Traumatic Brain Injury Study (ATBIS) Investigators for the Australian. New Zealand Intensive Care Society Clinical Trials Group. Epidemiology and 12-month outcomes from traumatic brain injury in Australia and New Zealand. J Trauma. 2008;64:854-62.

6. Vik A, Nag T, Fredriksli OA, et al. Relationship of "dose" of intracranial hypertension to outcome in severe traumatic brain injury. J Neurosurg. 2008;109:678-84.

7. Narayan RK, Kishore PR, Becker DP, et al. Intracranial pressure: to monitor or not to monitor? A review of our experience with severe head injury. J Neurosurg. 1982;56:650-9.

8. Saul TG, Ducker TB. Effect of intracranial pressure monitoring and aggressive treatment on mortality in severe head injury. J Neurosurg. 1982;56:498-503.

9. Juul N, Morris GF, Marshall SB, Marshall LF. Intracranial hypertension and cerebral perfusion pressure: influence on neurological deterioration and outcome in severe head injury. The Executive Committee of the International Selfotel Trial. J Neurosurg. 2000;92:1-6.

10. Balestreri M, Czosnyka M, Hutchinson $P$, et al. Impact of intracranial pressure and cerebral perfusion pressure on severe disability and mortality after head injury. Neurocrit Care. 2006; 4:8-13.

11. Brain Trauma Foundation, American Association of Neurological Surgeons, Congress of Neurological Surgeons, et al. Guidelines for the management of severe traumatic brain injury. VI. Indications for intracranial pressure monitoring. J Neurotrauma. 2007;24 Suppl 1:S37-44.

12. Sahjpaul R, Girotti M. Intracranial pressure monitoring in severe traumatic brain injury--results of a Canadian survey. Can J Neurol Sci. 2000;27:143-7.

13. Stocchetti N, Longhi L, Magnoni S, Roncati Zanier E, Canavesi K. Head injury, subarachnoid hemorrhage and intracranial pressure monitoring in Italy. Acta Neurochir (Wien). 2003;145:761-5.

14. Bulger EM, Nathens AB, Rivara FP, et al. Management of severe head injury: institutional variations in care and effect on outcome. Crit Care Med. 2002;30:1870-6.

15. Lane PL, Skoretz TG, Doig G, Girotti MJ. Intracranial pressure monitoring and outcomes after traumatic brain injury. Can $\mathrm{J}$ Surg. 2000;43:442-8.

16. Shafi S, Diaz-Arrastia R, Madden C, Gentilello L. Intracranial pressure monitoring in brain-injured patients is associated with worsening of survival. J Trauma. 2008;64:335-40.

17. Stuart GG, Merry GS, Smith JA, Yelland JD. Severe head injury managed without intracranial pressure monitoring. J Neurosurg. 1983;59:601-5.

18. Akopian G, Gaspard DJ, Alexander M. Outcomes of blunt head trauma without intracranial pressure monitoring. Am Surg. 2007; 73:447-50.

19. Forsyth RJ, Wolny S, Rodrigues B. Routine intracranial pressure monitoring in acute coma. Cochrane Database Syst Rev. 2010; (2):CD002043.

20. Stroup DF, Berlin JA, Morton SC, et al. Meta-analysis of observational studies in epidemiology: a proposal for reporting. Meta-analysis Of Observational Studies in Epidemiology (MOOSE) group. JAMA. 2000;283:2008-12.

21. Thompson HJ, Rivara FP, Jurkovich GJ, Wang J, Nathens AB, MacKenzie EJ. Evaluation of the effect of intensity of care on mortality after traumatic brain injury. Crit Care Med. 2008;36: 282-90.

22. Sichez JP, Melon E, Clergues F, Metzger J, Pertuiset B. Treatment of severe head injuries by external ventricular drainage and barbiturate therapy. Mortality and morbidity in 57 cases (author's transl). Neurochirurgie. 1981;27:205-12.

23. Mauritz W, Janciak I, Wilbacher I, Rusnak M, Australian Severe TBI Study I. Severe traumatic brain injury in Austria IV: intensive care management. Wien Klin Wochenschr. 2007;119: 46-55.

24. Griesdale DE, McEwen J, Kurth T, Chittock DR. External ventricular drains and mortality in patients with severe traumatic brain injury. Can J Neurol Sci. 2010;37:43-8.

25. Badjatia N, Carney N, Crocco TJ, et al. Guidelines for prehospital management of traumatic brain injury 2 nd edition. Prehosp Emerg Care. 2008;12 Suppl 1:S1-52.

26. Steyerberg EW, Mushkudiani N, Perel P, et al. Predicting outcome after traumatic brain injury: development and international validation of prognostic scores based on admission characteristics. PLoS Med. 2008;5:e165.

27. Salas M, Hofman A, Stricker BH. Confounding by indication: an example of variation in the use of epidemiologic terminology. Am J Epidemiol. 1999;149:981-3.

28. Huang SJ, Hong WC, Han YY, et al. Clinical outcome of severe head injury in different protocol-driven therapies. J Clin Neurosci. 2007;14:449-54.

29. Czosnyka M, Pickard JD. Monitoring and interpretation of intracranial pressure. J Neurol Neurosurg Psychiatry. 2004;75: 813-21.

30. Cremer OL, van Dijk GW, van Wensen E, et al. Effect of intracranial pressure monitoring and targeted intensive care on functional outcome after severe head injury. Crit Care Med. 2005;33:2207-13.

31. Chittock DR, Dhingra VK, Ronco JJ, et al. Severity of illness and risk of death associated with pulmonary artery catheter use. Crit Care Med. 2004;32:911-15.

32. Martini RP, Deem S, Yanez ND, et al. Management guided by brain tissue oxygen monitoring and outcome following severe traumatic brain injury. J Neurosurg. 2009;111:644-9.

33. Cook DJ, Walter SD, Cook RJ, et al. Incidence of and risk factors for ventilator-associated pneumonia in critically ill patients. Ann Intern Med. 1998;129:433-40.

34. Girard TD, Kress JP, Fuchs BD, et al. Efficacy and safety of a paired sedation and ventilator weaning protocol for mechanically ventilated patients in intensive care (Awakening and Breathing Controlled trial): a randomised controlled trial. Lancet. 2008;371:126-34.

35. Vukic M, Negovetic L, Kovac D, Ghajar J, Glavic Z, Gopcevic A. The effect of implementation of guidelines for the management of severe head injury on patient treatment and outcome. Acta Neurochir. 1999;141:1203-8.

36. Palmer SFACS, Bader MKMSN, Qureshi AD, et al. The impact on outcomes in a community hospital setting of using the AANS Traumatic Brain Injury Guidelines. J Trauma. 2001;50:657-64.

37. Patel HC, Menon DK, Tebbs S, Hawker R, Hutchinson PJ, Kirkpatrick PJ. Specialist neurocritical care and outcome from head injury. Intensive Care Med. 2002;28:547-53.

38. Fakhry SM, Trask AL, Waller MA, Watts DD, IRTC Neurotrauma Task F. Management of brain-injured patients by an evidencebased medicine protocol improves outcomes and decreases hospital charges. J Trauma. 2004;56:492-9.

39. Arabi YM, Haddad S, Tamim HM, et al. Mortality reduction after implementing a clinical practice guidelines-based management protocol for severe traumatic brain injury. J Crit Care. 2010;25: 190-5.

40. Kirkness CJ, Burr RL, Cain KC, Newell DW, Mitchell PH. Effect of continuous display of cerebral perfusion pressure on outcomes in patients with traumatic brain injury. Am J Crit Care. 2006;15:600 
Appendix: Search strategy used for MEDLINE and EMBASE to identify studies included in this systematic review

\section{MEDLINE (Pubmed)}

1. Subarachnoid bolt.tw

2. Subdural monitoring.tw

3. Intraparenchymal monitor.tw

4. Intraventricular drain.tw

5. Intracranial pressure monitor.tw

6. ICP monitor.tw

7. External ventricular drain.tw

8. Ventriculostomy.tw

9. EVD.tw

10. 1 or 2 or 3 or 4 or 5 or 6 or 7 or 8 or 9

11. Craniocerebral trauma/

12. Closed head injury.tw

13. Closed head trauma.tw

14. Traumatic brain injury.tw

15. Brain injury.tw

16. TBI.tw

17. CHI.tw

18. 11 or 12 or 13 or 14 or 15 or 16 or 17

19. 10 and 18

\section{EMBASE}

1. Subarachnoid bolt.tw

2. Subdural monitoring.tw

3. Intraparenchymal monitor.tw

4. Intraventricular drain.tw

5. Intracranial pressure monitor.tw

6. ICP monitor.tw

7. External ventricular drain.tw

8. Ventriculostomy.tw

9. EVD.tw

10. 1 or 2 or 3 or 4 or 5 or 6 or 7 or 8 or 9

11. Head injury/

12. Closed head injury.tw

13. Closed head trauma.tw

14. Traumatic brain injury.tw

15. Brain injury.tw

16. TBI.tw

17. CHI.tw

18. 11 or 12 or 13 or 14 or 15 or 16 or 17

19. 10 and 18 